\title{
TRABALHO E FORMAÇÃO PROFISSIONAL DO ATENDENTE DE CONSULTÓRIO DENTÁRIO E DO TÉCNICO EM HIGIENE DENTAL
}

\author{
WORK AND PROFESSIONAL QUALIFICATIONS OF DENTIST OFFICE ATTENDANTS AND \\ OF DENTAL HYGIENE TECHNICIANS
}

\author{
Márcia Boen Garcia Liñan 1 \\ Lúcia Emília Nuevo Barreto Bruno 2
}

Resumo Este artigo analisa a formação de egressos dos cursos de atendente de consultório dentário (ACD) e de técnico em higiene dental (THD), procurando compreender a importância dos cursos técnicos na melhoria do desempenho profissional, da renda individual e familiar, assim como a sua importância para uma melhor inserção no mercado de trabalho. Mostra que, apesar das deficiências assinaladas pelos egressos, a escola os qualificou adequadamente para o desempenho de suas funções. No entanto, as dificuldades por eles encontradas em termos de representação coletiva, a falta de prestígio social e a baixa credibilidade e respeito profissional que lhes consagram os cirurgiõesdentistas permanecem como problemas a serem enfrentados. A falta de legitimidade profissional que ainda os caracteriza faz com que os auxiliares da odontologia fiquem à mercê das oscilações do mercado de trabalho e das políticas de saúde. O artigo sustenta que a regulamentação dessas categorias de trabalhadores pode significar proteção técnica e ética, evitando a formação de monopólios profissionais e assegurando normas de eqüidade e justiça sociais para os profissionais da saúde bucal. Palavras-chave educação profissional; auxiliares em odontologia; curso de nível técnico; expectativas profissionais.
Abstract This article analyzes the qualifications of dental office attendant (DOA) and dental hygiene technician (DHT) graduates, seeking to understand the importance technical courses have not only in improving their professional performance, individual and family incomes, but also their impact on these professionals' better placement in the work market. It shows that, despite the deficiencies these graduates mention, their schooling qualified them appropriately to perform their duties. However, the difficulties these professionals face in terms of collective representation, the lack of social prestige, and the low levels of professional credibility and respect they get from dentists remain hurdles to be faced. The lack of professional legitimacy that characterizes their work causes dental care assistance workers to be at the mercy of work market and health policy oscillations. The article claims that regulating these worker categories may not only lead to technical and ethical protection and to preventing professional monopoly formation, but also ensure social equality and justice norms for oral health professionals.

Keywords professional education; dental care assistants; technical course; professional expectations. 


\section{Introdução}

"O problema não é mudar a 'consciência' das pessoas, ou o que elas têm na cabeça, mas o regime político, econômico, institucional de produção da verdade."

Michel Foucault

Este artigo trata da situação de trabalho e da formação dos egressos dos cursos de atendente de consultório dentário (ACD) e de técnico em higiene dental (THD), procurando compreender a importância dos cursos técnicos para melhorar a renda individual, familiar, bem como para facilitar sua inserção no mercado de trabalho.

Antes, porém, cabem algumas considerações acerca da situação em que se encontram esses trabalhadores para melhor situar o leitor. As categorias atendente de consultório dentário e técnico em higiene dental foram estabelecidas pelo Ministério da Educação e Cultura (MEC) e pelo antigo Conselho Federal de Educação (CFE), através do parecer n ${ }^{\circ} 460 / 75$, do MEC/CFE, da antiga lei $n^{\circ}$ 5.692/71 (Lei de Diretrizes e Bases da Educação Nacional LDB). Estes órgãos, ao definirem o ACD e o THD, descrevem suas ocupações, os requisitos essenciais para o exercício da função e os currículos dos cursos de formação, determinando a habilitação no nível do antigo segundo grau completo como escolarização mínima. Estabelece, ainda, que, sob supervisão do cirurgião-dentista, os ocupantes destas funções executam tarefas auxiliares no tratamento odontológico.

O Conselho Federal de Odontologia (CFO), por sua vez, a partir de entendimentos estabelecidos com a Associação Brasileira de Odontologia (ABO) e com outras instituições, tais como Federação Nacional dos Odontologistas (FNO), Associação Brasileira de Ensino Odontológico (Abeno), e o Departamento de Odontologia do Instituto Nacional de Assistência Médica e Previdência Social, resolveu, por meio da decisão $n^{\circ} 26 / 84$, definir normas para habilitação ao exercício do ACD e do THD. Estabeleceu a obrigatoriedade de inscrição e de pagamento de anuidade junto ao Conselho Regional de Odontologia (CRO), fixando para o THD e para o ACD, respectivamente, dois terços e um décimo do valor cobrado aos cirurgiões-dentistas.

Isto implica a existência de duas normatizações para essas ocupações, embora por parte do governo federal elas não tenham ainda sido regulamentadas em lei. Assim, a inscrição, bem como a exigência de pagamento de anuidade junto aos CROs são, a rigor, ilegais, pois somente a União, por meio de lei, estabelece as qualificações e as condições para o exercício profissional, tal como ocorre na regulamentação da atividade do técnico em prótese dentária, de acordo com a lei n 6.710, de 5 de novembro de 1979. 
Além disso, no artigo 5 ${ }^{\circ}$ inciso XXI, a Constituição Federal de 1988 estabelece: "As entidades associativas, quando expressamente autorizadas, têm legitimidade para representar seus filiados judicial ou extrajudicialmente". Isto significa que somente à União compete estabelecer a obrigação de inscrição nos conselhos profissionais das diferentes categorias.

E, no artigo 22, inciso XVI, afirma: “Compete privativamente à União legislar sobre a organização do sistema nacional de emprego e condições para o exercício de profissões". Também na lei no 9.394/96, que estabelece as diretrizes e bases da educação nacional (LDB), existe referência à exclusividade de poder da União sobre a regulamentação do exercício profissional.

Mas, ainda assim, a decisão $\mathrm{n}^{\circ} 47 / 2003$, do CFO, alterou a denominação de atendente de consultório dentário para auxiliar de consultório dentário. Conforme decisão $n^{\circ} 24 / 2003$, a partir de $1^{\circ}$ de janeiro de 2004, a inscrição de auxiliar de consultório dentário, obtida mediante declaração do cirurgião-dentista (em que atestava que o trabalhador desempenhou tais funções pelo período de um ano, estando assim apto a inscrever-se como tal junto ao CRO), tornou-se provisória, com a duração de um ano, podendo ser prorrogada por igual período. A inscrição definitiva só poderá ser feita mediante apresentação de certificado de qualificação profissional básica emitido por estabelecimentos de ensino autorizados pelo Ministério da Educação, pela Secretaria Estadual de Educação, Conselho Estadual de Educação ou órgão similar.

A profissão de técnico em prótese dentária, por sua vez, que também é exercida por um trabalhador auxiliar da área da odontologia, já é regulamentada pela União, pela lei $\mathrm{n}^{\circ} 6.710 / 79$ e pelo decreto $\mathrm{n}^{\circ} 87.689 / 82$. Esta regulamentação estabelece a inscrição desses profissionais junto ao CROs e a obrigatoriedade de pagamento de anuidade.

Atualmente, encontra-se na Comissão de Trabalho, de Administração e Serviço Público (CTASP) da Câmara Federal, em Brasília, o projeto de lei $\mathrm{n}^{\circ}$ 1.140/03, que busca regularizar a profissão de ACD e de THD - que passarão, com a aprovação definitiva do projeto, a se chamar auxiliar de saúde bucal (ASB) e técnico em saúde bucal (TSB). Cabe ressaltar que a denominação deste último já foi estabelecida pelo MEC, quando instituiu os Referenciais curriculares nacionais para a educação profissional de nivel técnico, publicado em 2000 e disponível na internet, com base no parecer $n^{\circ}$ 16/99 e na resolução n ${ }^{\circ}$ 04/99, ambos do Conselho Nacional de Educação/Câmara de Educação Básica (CNE/CEB).

O Ministério do Trabalho (MTb), por outro lado, quando elaborou a nova Classificação Brasileira de Ocupações (CBO), determinou outras denominações para a categoria vista como ocupação e não profissão - uma vez que ela não está regulamentada em lei pela União -, quais sejam: atendente de clínica dentária, atendente de gabinete dentário, auxiliar de serviço odon- 
tológico, auxiliar de dentista. As atribuições definidas pelo MTb para o técnico (THD) são, em nosso entender, equivocadas e não estão previstas no Ministério da Saúde (MS), MEC e CFO. São elas: triar pacientes; realizar anamnese do paciente; elaborar a anamnese do paciente; interpretar informações técnicas; sugerir ao cliente opções de materiais de higiene bucal e tipos de prótese; estimar prazos; confeccionar moldeiras e provisórios; escolher a cor direto com o paciente; restaurar dentes; além de executar os seguintes procedimentos odontológicos sob supervisão do cirurgião-dentista: esculpir materiais; moldar arcada dentária (o termo arcada dentária caiu em desuso; atualmente utiliza-se arco dentário); fixar provisórios; verificar resultado dos procedimentos; comunicar-se; divulgar serviços e técnicas; instruir na instalação e higienização de próteses dentárias (a higienização de próteses dentárias é permitida ao THD).

Os procedimentos listados são atribuições pertinentes exclusivamente ao cirurgião-dentista, daí serem equivocados. A anamnese é de responsabilidade dele, que deve estar atento às doenças sistêmicas dos pacientes antes de dar início ao ato operatório. Qualquer falha no atendimento, por descuido profissional, pode caracterizar negligência, imperícia ou imprudência do cirurgião-dentista, conforme estabelece a legislação em vigor relativa ao perfil desse profissional no Brasil. A sugestão de tipos de próteses e prazos para o tratamento também compete a ele. Faz parte da documentação odontolegal do cirurgião-dentista, no item previsão de custos, a escolha da prótese pelo paciente, além do que este deve assinar a opção de escolha do trabalho profissional a ser realizado. Da mesma forma, a estimativa de prazo deve ser avaliada e informada ao paciente pelo cirurgião-dentista. Informa o Código de Ética Odontológica (CEO) no capítulo V, Do relacionamento, seção I, Com o paciente, artigo $7^{\circ}$, inciso XII que: "Constitui infração ética: (...) iniciar qualquer procedimento ou tratamento odontológico sem o consentimento prévio do paciente ou do seu responsável legal, exceto em casos de urgência ou emergência" (CEO/CFO, 2003).

Escolha de cor, restauração dos dentes, moldagens de arcos dentários, fixação de provisórios e resultado de procedimentos são atribuições privativas do cirurgião-dentista. Somente a ele compete executar tais funções, que não podem ser delegadas aos auxiliares nem aos estagiários de odontologia, quando houver, ou a profissionais que ainda não completaram a graduação e, portanto, não estão inscritos no CRO. Conforme estabelece o mesmo código, no capítulo V, Do relacionamento, seção I, Com o paciente, artigo $9^{\circ}$, inciso IX: “Constitui infração ética: (...) utilizar-se de serviços prestados por profissionais não habilitados legalmente ou por profissionais da área odontológica, não regularmente inscritos no conselho regional de sua jurisdição" (CEO/CFO, 2003). 
Quanto ao item comunicação, a divulgação de serviços e técnicas é expressamente proibida pelo CFO. O atual Código de Ética Odontológica atesta na seção I, Do anúncio, da propaganda e da publicidade, artigo 34, inciso III: "Constitui infração ética (...) anunciar técnicas de tratamento, equipamentos e instalações" (CEO/CFO, 2003).

Instruir na instalação de próteses dentárias é competência do cirurgiãodentista. Ainda de acordo com o código, no capítulo V, Do relacionamento, seção I, Com o paciente, artigo $7^{\circ}$, inciso IV: "Deixar de esclarecer adequadamente os propósitos, riscos, custos e alternativas do tratamento" também constitui infração ética.

O pessoal técnico, convidado pelo MTb para elaboração das atribuições do ACD e do THD, demonstrou falta de conhecimento da resolução do CEO anterior, resolução $\mathrm{n}^{\circ}$ 179/91, do CFO, de 19 de dezembro de 1991, publicada em 1992, revogada, com a aprovação da atual resolução ${ }^{\circ} 42$, do CFO, exarada em 20 de maio de 2003. As associações de classe e o CFO deveriam solicitar ao MTb uma reavaliação da CBO.

Independentemente das explicações, o que se nota é a completa falta de critério e observância das leis, portarias, decisões e resoluções estabelecidas pela União, MEC, MS e CFO. Muitas dessas informações são desencontradas e acabam por confundir os auxiliares em seus estudos e atividades práticas.

A União deveria garantir a regulamentação de algumas ocupações, especialmente a dos auxiliares de saúde bucal, cuja complexidade de trabalho e de ações exige responsabilidade no trato com o usuário dos programas. A Lei Maior da República estipula critérios para que os serviços de saúde sejam corretamente realizados, tendo em vista a dignidade da pessoa humana. Entretanto, não promove a igualdade de condições de todas as categorias de auxiliares da saúde.

Esses são desafios que requerem uma política clara de valorização do trabalhador da saúde por meio da legitimação dessas categorias de auxiliares, promovendo um processo de revisão da 'legislação' de regulação das ocupações, no sentido de adequá-las às suas atividades, ao campo de exercício ainda não regulamentado.

Essa questão merece atenção cuidadosa por parte das entidades da categoria, do MTb, dos serviços públicos e do CNE, que deveriam, por meio de consenso, buscar a regulamentação desses auxiliares e determinar suas funções, uma vez que aquelas estabelecidas pela Classificação Brasileira de Ocupações, pelo antigo Conselho Federal de Educação - atual Conselho Nacional de Educação -, e as elencadas pelo quadro do Serviço Público são distintas e conflitantes. Há ainda outra contradição, quando esse trabalhador se submete a concurso público, uma vez aprovado, dele são exigidos, como documentos de admissão ao trabalho, o certificado de ACD (se o con- 
curso foi para ACD) e o diploma de THD (se o concurso foi para THD), assim como a carteira de inscrição junto ao CRO local. Levando-se em conta que estas categorias não foram ainda regulamentadas em lei pela União, esta última exigência não tem amparo legal.

Esta exposição, um tanto longa, da situação legal dos trabalhadores aqui em discussão é importante para que o leitor possa melhor avaliar a importância de uma legislação clara no que diz respeito ao exercício das ocupações e profissões no âmbito da saúde.

\section{O universo da pesquisa}

Este artigo apóia-se em dados obtidos em pesquisa realizada durante os anos de 2004 e 2005 com egressos dos cursos de formação de ACD e THD, ofertados tanto por instituições públicas quanto privadas, na Grande São Paulo. Foram enviados 400 questionários: 147 para os THDs, dos quais 45 retornaram, e 253 para os ACDs, que devolveram 106 preenchidos. Do total de 400, 14 foram devolvidos em branco e 7 tinham endereço desconhecido. Os endereços desses trabalhadores foram obtidos através do Conselho Regional de Odontologia, mediante apresentação do projeto de pesquisa desenvolvido na Faculdade de Educação da Universidade de São Paulo (USP). O envio dos questionários foi aprovado pelo Comitê de Ética em Pesquisa da Faculdade de Odontologia da USP.

A amostra constitui-se, portanto, de 151 questionários respondidos $(\mathrm{N}=151)$, o que representa $37,75 \%$ do total de questionários enviados, pois, pelo erro de estimação, para um intervalo de confiança de $95 \%$ e de erro máximo de $10 \%$, num total de 130 questionários respondidos. Por meio dos questionários aplicados foi possível caracterizar o público atendido pelos cursos, consoante: faixa etária, grau de escolaridade, situação no mercado de trabalho, condições de trabalho, renda familiar e individual, moradia, expectativas dos egressos com relação ao curso realizado, relação dos cursos com as atividades que desenvolviam e, por fim, as críticas e sugestões.

\section{Características dos egressos: sexo, idade e escolaridade}

Da totalidade de egressos constantes na amostra, a maior parte é constituída por mulheres (103 ACDs; 44 THDs); quanto aos homens, são 3 ACDs e $1 \mathrm{THD}$, cenário que gerou percentuais de $97 \%$ para $\mathrm{ACD}$ e $98 \%$ para $\mathrm{THD}$; e $3 \%$ para $\mathrm{ACD}$ e $2 \%$ para $\mathrm{THD}$, respectivamente.

Quanto à faixa etária, a maior concentração está entre 41 e 50 anos para os ACDs (31,1\%), seguida de 31 a 40 anos $(29,2 \%)$, de 51 a 60 anos $(23,6 \%)$, 
de 20 a 30 anos $(11,3 \%)$, de 61 a 70 anos $(3,8 \%)$ e de 18 a 20 anos $(0,9 \%)$, sendo que os 3 do sexo masculino (3\%) estão compreendidos na faixa etária dos 31 aos 40 anos, a de segunda maior concentração. Para os THDs, a maior concentração é na faixa de 31 a 40 anos (33,3\%), de 20 a 30 anos (31,1\%), de 41 a 50 anos $(26,7 \%)$ e de 51 a 60 anos $(8,9 \%)$, sendo que apenas um é do sexo masculino (2\%), com idade entre 31 e 40 anos, portanto, incluído na faixa etária de maior concentração de egressos.

Quanto à escolaridade, 71,7\% dos ACDs têm Ensino Médio completo, o que facilita o itinerário de estudo para THD. A segunda maior concentração é de egressos com o Ensino Médio incompleto (12,3\%). Com apenas o Ensino Fundamental ( $5^{\mathrm{a}}$ à $8^{\mathrm{a}}$ série), 7,5\%. Esses três níveis de escolaridade concentram juntos $91,5 \%$ de egressos. Os restantes $8,5 \%$ possuem o Ensino Superior incompleto $(2,8 \%)$ e o Ensino Superior completo $(5,7 \%)$.

No que diz respeito ao THD, a maior concentração também é no nível de escolaridade de Ensino Médio completo (68,9\%). Com o Ensino Superior completo, 17,8\%; e, com o Ensino Superior incompleto, 8,9\%. O total dos três níveis é de 95,6\%. Os restantes 4,4\% referem-se àqueles que têm o Ensino Fundamental ( $1^{\mathrm{a}}$ à $4^{\mathrm{a}}$ série), com $2,2 \%$, e Ensino Fundamental $\left(5^{\mathrm{a}}\right.$ à $8^{\mathrm{a}}$ série), com 2,2\%. Observa-se, portanto, que o grau de escolaridade predominante entre os THDs é o Ensino Médio, embora não seja desprezível a taxa de 17,8\% de trabalhadores com o diploma universitário. Conclui-se que os egressos dos cursos apresentam nível de escolaridade muito superior ao público-alvo visado pelo MEC, ou seja, estudantes do Ensino Médio e Técnico.

Quanto ao local de moradia, a maior parte dos ACDs (79,2\%) vive nos bairros de São Paulo; na periferia, $15,1 \%$, e poucos no centro $(5,7 \%)$. Com relação aos THDs, pode-se observar que também se concentram mais nos bairros $(82,2 \%)$ do que na periferia $(17,8 \%)$. No que diz respeito ao acesso à infra-estrutura, são poucos os ACDs que não possuem saneamento básico, como água encanada $(0,9 \%)$, coleta de lixo (1\%), esgoto público $(7,5 \%)$ e pavimentação $(8,5 \%)$. Iluminação pública e luz elétrica, todos os ACDs têm. Quanto aos THDs, todos os pesquisados possuem infra-estrutura.

Os transportes, para 70,75\% dos ACDs, são considerados suficientes, levando em conta o trajeto do local da moradia até o trabalho. Para 28,3\%, são insuficientes, e apenas um deles afirmou não ter acesso a meios de transporte $(0,95 \%)$ para o trabalho. Para os THDs, a situação se repete, com suficiência de transportes para a maioria $(80 \%)$. Poucos dizem ter insuficiência de transportes (18\%), e apenas um deles disse não ter acesso $(2 \%)$.

Quanto ao porte da moradia, o ACD se concentra em residências de três a quatro cômodos $(54,7 \%)$, a percentagem dos que vivem em residências com mais de quatro cômodos soma 39,6\%, e, finalmente, em habitações de um ou dois cômodos é de 5,7\%. O THD se concentra, em residências com 
mais de quatro cômodos (48,9\%), enquanto a percentagem dos que vivem em residências com três ou quatro cômodos é um pouco menor (33,3\%), e poucos em habitações de um ou de dois cômodos $(17,8 \%)$, pois a renda destes é bem maior em relação ao ACD.

Quanto à conservação da moradia para o ACD, observa-se que a maioria possui a residência conservada $(69,8 \%)$, algumas em construção $(12,3 \%)$, algumas construções recentes $(10,4 \%)$ e poucas se encontram deterioradas $(7,5 \%)$. Para o THD, a maior parte das casas também está conservada $(71,1 \%)$, algumas são de construção recente $(20 \%)$, algumas em construção $(2,2 \%)$ e poucas estão deterioradas $(6,7 \%)$. Observa-se, portanto, situação muito semelhante àquela declarada pelos ACDs.

Em relação à condição de ocupação da moradia, a maioria dos ACDs possui casa própria quitada $(64,2 \%)$, em seguida vêm os que moram em casas alugadas $(16 \%)$ e, finalmente, os que têm moradias financiadas $(11,3 \%)$. Os $8,5 \%$ restantes declararam outras condições de ocupação, como as recebidas por herança, emprestadas, pertencente aos pais ou parentes (pessoa não moradora, parente ou não). Entre os THDs, a maioria possui moradia própria quitada $(48,9 \%)$, em seguida vêm as moradias alugadas $(22,2 \%)$. As moradias financiadas vêm em terceiro lugar $(17,8 \%)$ e, finalmente, aparecem aquelas inseridas em outras condições, como as recebidas por herança compartilhada com vários donos, emprestadas, pertencem aos pais, os terrenos para a construção são dos pais, ou da família $(11,1 \%)$.

\section{Situação no mercado de trabalho e renda}

Entre os ACDs, 84,9\% encontravam-se empregados no momento da realização da pesquisa, 8,5\% estavam desempregados, 4,7\% eram ingressantes e 1,9\%, inativos. Quanto aos THDs, 89\% estavam empregados e $11 \%$ encontravam-se desempregados. Para estes, o desemprego resulta do nível de exigência do mercado de trabalho quanto à qualificação.

As rendas mensais individuais dos ACDs ocupados é baixa: 48\% recebem em torno de 2 a 4 salários mínimos (SM); $29 \%$ recebem de 0 a 2 SM; $11 \%$, de 4 a 6 SM; $8 \%$ não responderam e $4 \%$ não recebem nada. Ao observar a renda mensal familiar, nota-se que predomina a faixa situada entre $2 \mathrm{e}$ 4 SM (28,3\%), seguida do grupo que recebe entre 4 e 6 SM $(20,8 \%)$, e de 6 a 10 SM, encontram-se apenas $17,9 \%$. Os restantes $34 \%$ estão incluídos na faixa de 0 a 2 SM, totalizando 4,7\%; na faixa de 10 a 15 SM estão 6,5\%; de 15 a 30 SM estão 2,8\%; apenas $1 \%$ não recebe nada, e $18 \%$ não responderam. As rendas mensais individuais dos THDs ocupados são melhores do que as recebidas pelos ACDs: 33,3\% ganham de 2 a 4 SM; 31,1\%, de 4 a 6 SM. Em seguida, vêm os que recebem de 0 a 2 SM $(15,6 \%)$; de 6 a 10 SM 
$(11,1 \%)$; e 8,9\% não têm nenhuma renda. Ao se observar a renda mensal familiar, nota-se que a concentração maior está entre os que recebem entre 6 e 10 SM (26,7\%), seguidos de 4 a 6 SM (17,8\%); com 10 a 15 SM, 15,6\%; com 15 a 30 SM, 13,3\%. Entre os que ganham de 2 a 4 SM, como renda inicial, a percentagem é de $15,6 \% ; 11 \%$ não responderam. Esses dados mostram que o nível de renda familiar dos THDs é bem mais alto do que o dos ACDs.

Na pesquisa observou-se que, tanto no caso do ACD quanto no do THD, as mulheres se iniciam na profissão em idade mais avançada do que os homens e permanecem por mais tempo na função, auxiliando o dentista, principalmente nos serviços públicos. As respostas dadas às questões relativas ao mercado de trabalho e à valorização profissional levantam uma série de expectativas e dificuldades que, em termos gerais, poderíamos sintetizar nos termos que se seguem.

Primeiramente, quanto ao ACD, suas expectativas são: valorização pelo empregador e melhores salários devido ao risco à saúde a que se expõe no exercício da função; maiores chances no mercado de trabalho para pessoas com mais de 30 anos; ampliação do campo de trabalho para absorver um maior número destes profissionais, o que por sua vez aumentaria o interesse das pessoas em qualificar-se; encaminhamento direto para postos de trabalho após o término do curso e aumento do número de vagas tanto no serviço público como no setor privado. Quanto ao quesito dificuldades, colocação no mercado é a mais recorrente nas respostas obtidas na pesquisa.

Para o THD, a maior expectativa é que o mercado de trabalho, muito restrito no âmbito do serviço público, se expanda, já que no setor privado raramente se encontra THD e, quando é encontrado, o salário é muito baixo. Além disso, o THD acaba exercendo a função de ACD, recepcionista, trabalho externo (banco) e outros, ou seja, grande parte das expectativas desse trabalhador direciona-se para a ampliação de postos de trabalho no serviço público onde julga ter mais oportunidades. Quanto às dificuldades, poderíamos sintetizá-las em mercado de trabalho restrito, salário muito baixo. Nas prefeituras exige-se demais do THD, que passa a ter várias atividades que não fazem parte de sua função; cinco anos, ou mais, após a formação, alguns não conseguem trabalhar ainda na função, faltam concursos públicos e, na área privada, poucas são as contratações; no setor privado, raramente se encontra THD.

Esses trabalhadores consideram-se qualificados para o trabalho, porém observa-se a apreensão que sentem quanto à possibilidade do desemprego, do rebaixamento dos salários e quanto à precarização do trabalho, o que é um agravante, neste caso, se considerarmos que o setor da saúde apresenta condições de risco para os seus trabalhadores. 
Embora reconheçam a importância dos cursos que os qualificam, gostariam de ser encaminhados ao mercado de trabalho pelas instituições formadoras. Apontam a falta de oportunidades e a exigência pelos empregadores de experiência comprovada como entraves à inserção dos mais jovens no mercado de trabalho. As funções também não estão bem delimitadas. De acordo com as respostas dos auxiliares, eles acabam realizando uma série de outras atribuições, ultrapassando muitas vezes sua carga horária. Sentem desgaste físico e sofrimento psíquico decorrentes de múltiplos fatores: más condições de trabalho; isolamento no exercício da função; ausência de valorização de seu trabalho por parte do dentista e das instituições que os contratam; sobrecarga de trabalho decorrente da redução de pessoal auxiliar imposta pelas políticas de contenção de despesas tanto do Estado quanto das empresas e dos consultórios privados. Muito se tem escrito sobre o sofrimento psíquico do trabalhador do setor bancário, fabril e químico, assim como de muitos outros. No entanto, um estudo sobre o sofrimento psíquico dos trabalhadores auxiliares do setor da saúde bucal está ainda por ser feito.

\section{Formação profissional do ACD e do THD}

Os avanços da pesquisa científica e a sofisticação dos equipamentos no campo da odontologia nas últimas décadas foram significativos, abrindo novos campos de atuação para o dentista tanto na prevenção quanto na recuperação e cura de pacientes. Nesta perspectiva, cursos de formação, inclusive continuada, dos auxiliares da odontologia são fundamentais para o bom desempenho do cirurgião-dentista.

No Brasil, esta questão é da maior importância se considerarmos a origem de classe desses trabalhadores. Em geral, são oriundos de famílias de baixa renda, com problemas na formação básica, não por falta de empenho nos estudos ou de capacidade de aprender, mas por não terem tido acesso a uma educação mais consistente e, principalmente, a bens culturais que neste país constituem privilégios de poucos.

Os egressos valorizam muito os cursos de formação profissional que fizeram, mas, ao mesmo tempo, apontam a lacuna existente entre estes e uma política de emprego, bem como a necessidade de formação de acordo com as necessidades do mercado. A maioria dos egressos está empregada e se considera empregável. Os desempregados, no entanto, se vêem obrigados a uma ocupação insatisfatória, mal paga, aquém de sua qualificação. Para os egressos, empregabilidade é muito mais do que obter emprego; significa, sobretudo, manter-se no emprego. Daí a importância da educação continuada, mesmo após os cursos de formação profissional no serviço público, a fim de 
possibilitar atualização constante das qualificações adquiridas, atendendo sempre às novas necessidades de aprendizagem, às novas competências comportamentais e de comunicação, gerando novas habilidades, solicitadas pelas formas de trabalho atuais.

A atuação do Estado é fundamental junto a este segmento de trabalhadores, propiciando-lhes formação e qualificação técnica, com o objetivo de recuperar o déficit de conhecimento nos ensinos fundamental e médio.

Existe, de acordo com o parecer $\mathrm{n}^{\circ} 16 / 99$, do CNE/CEB, um aspecto importante no que diz respeito à qualificação profissional de categorias como a de auxiliares, no artigo $4^{\circ}$, parágrafo $2^{\circ}$ : o aluno que concluir um ou mais cursos de qualificação profissional fará jus apenas aos respectivos certificados de qualificação profissional, que deverão explicitar as competências profissionais da qualificação e o título da ocupação. A cada módulo cursado pelo aluno, este deverá receber um certificado. É importante citar parte desse parecer:

“Os cursos referentes a ocupações que integrem itinerários profissionais de nível técnico poderão ser oferecidos a candidatos que tenham condições de matrícula no ensino médio. Esses alunos receberão o respectivo certificado de conclusão da qualificação profissional de nível técnico. Para a obtenção de diploma de técnico na continuidade de estudos será necessário concluir o ensino médio. Os alunos devem ser alertados quanto a esta situação." (Brasil, 1999).

Em relação à formação do THD, deve-se voltar o olhar para o decreto $\mathrm{n}^{\circ}$ 5.154/04 (que revogou o decreto $\mathrm{n}^{\circ} 2208 / 97$ ), complementado pelo parecer $\mathrm{n}^{\circ} 39 / 04$, do CNE/CEB, que, no artigo $4^{\circ}$, parágrafo $1^{\circ}$, incisos I, II e III, estabelece que:

“a educação profissional técnica de nível médio e o ensino médio dar-se-ão de forma integrada, oferecida somente a quem já tenha concluído o ensino fundamental, sendo o curso planejado de forma a conduzir o aluno à habilitação profissional técnica de nível médio, na mesma instituição de ensino, contando com a matrícula única para cada aluno, concomitante ou subseqüente para aqueles que já tenham concluído o ensino médio". (Brasil, 2004).

O decreto $\mathrm{n}^{\circ} 5.154 / 04$, no artigo $1^{\circ}$, incisos I, II e III, respectivamente, organiza a educação profissional em três níveis: formação inicial e continuada de trabalhadores; educação profissional técnica de nível médio e educação profissional tecnológica de graduação e de pós-graduação.

Atualmente, o que se argumenta é a dualidade do mercado de trabalho, o de baixa e o de alta qualificação, conduzindo a uma fragmentação da classe trabalhadora. Porém, na perspectiva dos trabalhadores, o desejo é de 
uma luta pela educação, em que o trabalhador como sujeito se apropria de conhecimentos e habilidades para que possa ter uma visão crítica da realidade, ser valorizado e ter atendidos seus interesses e necessidades sociais.

É importante a transformação da educação e do funcionamento dos recursos disponíveis, evitando mergulhar nos espelhismos, muitas vezes enganadores, que orientam as reformas educacionais, marcadas pela importação dos modelos estrangeiros. Uma pedagogia baseada na autonomia, na ética, na dignidade humana, no clima democrático para a capacitação dos técnicos é de extrema importância, pois o que se deseja é que esses profissionais possam se tornar multiplicadores, com melhor nível de escolaridade, com política de igualdade e eqüidade, tendo a ética profissional como fundamento.

O que se espera desse trabalhador é uma visão da saúde como direito pelo qual se deve lutar numa democracia participativa, utilizando-se de todos os meios para a construção crítica e de apropriação do conhecimento, centrada na relação dinâmica do profissional e do atendido, que possuem papéis distintos mas complementares, sabendo valorizar a linguagem verbal e não verbal, sendo o sujeito atendido visto como um todo afetivo, cognitivo e social. Um mediador que ajuda na construção do conhecimento e auxilia no tratamento (e constrói junto), conhecedor da realidade para ajudar a intervir e a buscar soluções.

Segundo Tartuce (2004), a formalização da qualificação em classificações profissionais significou, na França do pós-guerra, a padronização dos conteúdos da qualificação: cada profissão, cada posto de trabalho correspondia a um nível escolar; uma vez adquiridos os conhecimentos dessa categoria profissional, o trabalhador poderia permanecer sem que lhe exigissem novas aprendizagens. Havia um ordenamento social das profissões e da estrutura de cargos e salários relativamente sólido e estável, legitimado e hierarquizado pelo diploma e tempo de formação.

Todavia, com as mudanças ocorridas na organização do trabalho, que exigem não apenas conhecimentos formais estabelecidos pelo diploma, mas também amplas habilidades, como iniciativa, responsabilidade, autonomia, criatividade, cooperação, liderança, entre outras, surge a necessidade do trabalhador polivalente.

Conforme Tartuce:

"A ênfase na 'polivalência', entendida como um conjunto de capacidades que possam enfrentar a complexidade e a imprevisibilidade do 'novo' modo de produzir, significa a passagem do conceito de 'qualificação' para o de 'competência'. A competência pode ser definida como a tradução dessas capacidades numa tomada de iniciativa e num assumir de responsabilidades por parte do trabalhador perante os eventos produtivos - situações surpreendentes que ocorrem na 
produção (Zarifian, 1997 e 1998). A competência é, pois, um atributo que remete à subjetividade do indivíduo e relaciona-se com a sua capacidade de mobilizar os saberes e as atitudes necessárias para, de forma autônoma, resolver problemas em uma situação específica (Machado, 1998; Tanguy, 1997a e 1997c)" (Tartuce, 2004, p. 359-360).

No Brasil, informa Tartuce, nunca tivemos estabilidade, a relação diplomacargo-salário nunca foi regulamentada e as classificações profissionais não têm sentido empírico; o reconhecimento da qualificação sempre se deu de forma individual, pelo registro na carteira de trabalho, o que coloca o trabalhador na mão da empresa, já que é ela quem decide se qualifica ou não o funcionário, numa ação unilateral. Desta forma, acrescenta a autora, em um contexto de forte desemprego, segmentação do mercado de trabalho e flexibilização dos vínculos empregatícios, torna-se ainda mais importante recuperar a visão que afirma ser a qualificação construída socialmente, a fim de se observarem as estratégias desenvolvidas pelas diferentes categorias de trabalhadores para inserir-se ou manter-se no mercado de trabalho.

Se o diploma deixa de ser condição suficiente para a inserção e manutenção no mercado de trabalho e se, simultaneamente, as exigências nesse domínio e no âmbito das qualidades pessoais não cessam de aumentar, expressas pela 'polivalência', como explicar que essa tendência à maior 'qualificação' não seja acompanhada de aumentos de salário? Mais ainda, se pessoas 'qualificadas' não encontram lugar no mercado de trabalho, isso nada mais significa que estão 'desqualificadas', já que “certas qualificações sem emprego, tal como é o caso dos diplomados que não encontram o trabalho pretendido, cessam de ser então, socialmente, qualificações" (Naville apud Tartuce, 2004, p. 377).

A pergunta aberta feita aos trabalhadores em relação aos cursos de formação de ACD e THD nos deu condições de identificar os problemas que mais os atingem. No que diz respeito aos ACDs, são eles: dificuldade em conciliar horário de curso com trabalho; existem poucos profissionais que ministram o curso e faltam escolas especializadas; há necessidade de mais cursos de qualificação e requalificação; deve haver maior divulgação de cursos, locais próximos do local de trabalho, preços condizentes com o poder aquisitivo dos auxiliares, com uma pequena taxa de inscrição; seria bom se os cursos encaminhassem o aluno para o mercado de trabalho, pois a disputa é grande, após os 40 anos as chances são mínimas; valorização e importância de se trabalhar a quatro mãos, pois na universidade este valor não tem sido dado; maior divulgação e disponibilidade de horário, liberação do trabalho e compreensão dos colegas; mais cursos de reciclagem profissional, pois o serviço público dá pouca oportunidade para seus técnicos e auxiliares, a maioria dos cursos ofertados é de nível superior, e não de nível técnico. 
Para os THDs, as reivindicações são: cursos profissionalizantes mais freqüentes, de maior duração, seriam fundamentais; cursos mais baratos, todos devem ter um bom salário, as empresas poderiam facilitar os horários, cursos oferecidos em três horários para se ter mais de uma opção; restrição à atuação dos ACDs e THDs nos serviços públicos, o que provoca desmotivação para se aprimorar; curso de atualização para as funções de ACD e THD, melhores condições de salário e trabalho; reciclagem, divulgação de cursos mostrando a importância do trabalho a quatro e seis mãos facilitando a atuação do dentista; o THD é um curso interessante, mas não tem campo de trabalho, poucos conseguem emprego.

Na totalidade dos questionários, observa-se uma valorização dos cursos de qualificação e habilitação, mas evidencia-se também que estes não garantem emprego e que há muita mão-de-obra disponível no mercado de trabalho. A vontade de aprender é grande e resulta dos sucessos e fracassos da aprendizagem anterior. Também o desejo de trabalhar e colocar em prática o aprendizado resgata a importância da qualificação e habilitação, da escolaridade, até de um nível de escolaridade muito superior ao exigido pelas funções desempenhadas.

Quando perguntados se em algum momento do curso foram abordadas questões relativas aos direitos e deveres dos trabalhadores, 91,5\% dos ACDs informaram que sim, 6,6\% responderam negativamente e 1,9\% não responderam. Dentre os temas apresentados, os mais abordados foram segurança no trabalho (direito) e postura no ambiente de trabalho (dever).

Quanto aos THDs, 95,6\% afirmaram ter tido nos cursos conteúdos relativos aos direitos e deveres do trabalhador. Apenas 4,4\% responderam não ter tido contato com essas questões nos cursos realizados. Da mesma forma, os temas mais abordados foram os relativos a segurança no trabalho e a postura profissional.

Foi perguntado ao grupo de ACDs se o curso trouxe modificações na vida pessoal. A maioria respondeu que $\operatorname{sim}(96,2 \%)$, sendo que 1,9\% disse não e 1,9\% não respondeu. Para a mesma pergunta formulada aos THDs, $97,8 \%$ responderam que, de fato, a experiência do curso provocou mudança na vida pessoal, e somente 2,2\% afirmaram não ter tido qualquer alteração.

Em relação à questão se os empregadores valorizam os trabalhadores que realizam cursos profissionalizantes, 65,1\% dos ACDs responderam que sim, 33\% disseram não e 1,9\% não responderam. Os que responderam sim informaram que isto se deve à valorização dos cursos de atualização e de especialização, mas, para os que responderam não, o fator principal é que os empregadores valorizam a experiência e o mercado de trabalho é restrito.

Quanto aos THDs, para a mesma pergunta, a maioria $(64,4 \%)$ respondeu que sim; que os empregadores valorizam o curso profissionalizante. No entanto, 35,6\% responderam negativamente. Dentre os que responderam 
sim, a razão apontada é valorização da especialização e dos cursos de atualização por parte dos empregadores. Dos que responderam não, a não valorização dos trabalhadores egressos dos cursos por parte dos empregadores se deve ao fato do mercado de trabalho ser muito restrito.

Quanto à dificuldade na realização de outros cursos, os ACDs informaram que muitos são os fatores, dentre eles o principal é a dificuldade financeira, considerando que eles devem comprar materiais e instrumentos. Em seguida, vêm a falta de divulgação e de tempo para realizá-los.

Pelo resultado alcançado nos questionários, pode-se notar que o conhecimento adquirido gerou oportunidades de trabalho. Segundo as respostas obtidas na pesquisa, a renda, ou as deferências que um dia poderiam vir a receber em função dos cursos realizados, não tem grande importância. As conquistas regulatórias a serem alcançadas foram o elemento mais destacado como recompensa de um processo de aprendizado social, uma vez que possuem os currículos mínimos para certificação profissional, com direitos e deveres bem estabelecidos, o que tende a refletir as dificuldades dessas profissões no sentido de se profissionalizarem plenamente. As respostas dos auxiliares em relação à falta de regulamentação pela União assinalam que, se a tivessem obtido, poderiam recuperar seu status e passariam a ter uma remuneração mais justa.

Na maior parte dos questionários, aparece registrada uma série de reivindicações, todas elas girando em torno dessa questão: deveria haver mais proteção e fiscalização sobre nossas funções, o que se faz e o que se poderia fazer, a maioria não as executa, encontramos muitas barreiras; o reconhecimento legal da profissão é fundamental, assim como melhores condições de trabalho, valorização profissional por parte dos colegas e valorização financeira; reconhecimento profissional, pois somos pouco reconhecidos e mencionados nas publicações de jornais e revistas de entidades da mesma classe; reconhecimento do ACD e do THD pelo Ministério do Trabalho para que pudéssemos ter nossos direitos trabalhistas.

Como se pode ver, a falta de regulamentação jurídica da ocupação é um fator que incomoda esta categoria de trabalhadores.

A regulamentação institucional é um aspecto importante na constituição de uma profissão, pois dá credibilidade perante outros profissionais da saúde e até mesmo perante os usuários. É o saber legitimado. É a importância da identidade e do sentir-se membro de um determinado grupo profissional da área saúde, com direitos estabelecidos na forma de leis e regulamentos. Os indivíduos se beneficiam quando os grupos sociais se formam. Mesmo sabendo que a vida associativa impõe limites, ela não deixa de ser fonte de segurança, alegria e prazer, sendo gratificante poder compartilhar com outros um mesmo conjunto de regras. É neste âmbito que se elaboram os direitos profissionais e éticos. 
O estabelecimento das garantias da legislação sobre o exercício da profissão para esses trabalhadores, juntamente com a formação e relação de trabalho proporcionarão sentimentos de segurança, de identidade e de coesão, pois o pertencer a um grupo institucionalizado propicia a manutenção da cultura organizacional.

\section{Considerações finais}

Os resultados da pesquisa evidenciam um permanente conflito entre as duas dimensões da prática desses trabalhadores: a técnica e a política. As condições concretas de um município do porte de São Paulo, com um sistema de saúde em constante estruturação, com necessidades e demandas sociais cada vez mais críticas na periferia, tendem a ampliar as dimensões desse conflito, diante da insuficiência de instrumentos e de recursos humanos para atender às expectativas da comunidade e dos governos. $\mathrm{O}$ padrão de qualidade do trabalho é obtido, muitas vezes, graças ao empenho, à dedicação e ao compromisso da maioria dos auxiliares da saúde bucal.

Também nos cursos de enfermagem, o tema das relações humanas e profissionais é tratado em disciplinas de 'exercício profissional', de 'fundamentos do cuidado' ou com denominações que explicitam contribuições das ciências sociais e humanas à saúde. Parece haver maior exercício de leitura e traduções deste tipo de conhecimento em questões de gênero, poder, violência, entre outras. Isto pode se relacionar ao desenvolvimento da pósgraduação em enfermagem no Brasil e ao intenso investimento na capacitação do corpo docente dos cursos de graduação e na aquisição de novos aportes teóricos.

Nesse sentido, é importante a definição de um referencial do dia-a-dia para os trabalhadores da saúde bucal, facilitando o planejamento e a reflexão, para que o trabalho não fique na dependência do bom senso de cada um. É também fundamental a garantia de condições para que se construa um saber operante tanto em âmbito individual e biológico quanto na dimensão social e comunitária. Para tanto, esse trabalho exige o esforço de construção de uma identidade por meio de uma ação reguladora institucional e de caracterização dos serviços.

As novas tecnologias, o aumento do grau de complexidade organizacional, o crescimento das demandas sociais reforçam a necessidade da profissionalização por intermédio da regulamentação dos campos de atuação profissional.

Através da pesquisa realizada, pudemos constatar que o auxiliar de odontologia possui um nível de escolaridade superior ao dos trabalhadores 
empregados no setor formal da economia do município de São Paulo. Em relação à população brasileira e aos trabalhadores de todos os setores, ele é claramente elevado.

Para os trabalhadores ocupados, existe a necessidade de se aumentar o número de cursos de atualização profissional, melhorar as formas de divulgação, ofertar cursos de maior duração que desenvolvam mais atividades práticas e aprofundem conteúdos. Embora alguns elogios tenham sido feitos aos cursos, a freqüência com que aparecem é pouco significativa.

Tanto para os desempregados quanto para os ocupados é preciso oferecer horários de cursos que lhes facilitem a participação. Insistem que os professores sejam mais preparados para a docência, que se aumente a quantidade de material didático disponível para os alunos e que se supere o caráter por vezes repetitivo dos cursos. Pouco foi dito por parte dos egressos sobre transporte, alimentação e relacionamento com os professores, o que muitas vezes constituem problemas intransponíveis.

Acreditamos que os programas e cursos de formação profissional, sejam eles públicos ou privados, devam ser submetidos a contínuas avaliações institucionais acompanhadas de estudos de trajetórias de egressos no mercado de trabalho.

Finalmente, duas questões polêmicas apareceram no decorrer da pesquisa: a da inclusão legal dos auxiliares no trabalho odontológico e a sua rejeição por alguns profissionais da saúde, que vêem na luta desses trabalhadores pelo reconhecimento da profissão uma 'conspiração' .

A profissão tradicional de cirurgião-dentista não existe isoladamente, requer a força de trabalho de auxiliares e técnicos. Os auxiliares e técnicos se organizam em torno da autoridade que define e supervisiona suas atribuições. Esses profissionais 'básicos' (outsiders), mesmo que consigam a regulamentação que buscam, continuarão subordinados ao cirurgiãodentista (profissão estabelecida - established) (Elias e Scotson, 2000), ainda que se organizem em sindicatos ou associações. Nesse sentido, não se entende a razão pela qual muitos dentistas se sentem ameaçados pela regulamentação do trabalho dos auxiliares.

$\mathrm{Na}$ realidade, as ameaças derivam de outras fontes. Inicialmente da perda relativa do monopólio de um saber específico, uma vez que dado o aumento dos níveis de educação escolar por parte de segmentos expressivos da população, estes começam a questionar diagnósticos, formas de tratamento, ao mesmo tempo que aumentam os níveis de exigência dos usuários dos serviços odontológicos e crescem os grupos de proteção ao consumidor. Esses elementos resultam, muitas vezes, na perda de confiança nos profissionais e na queda do prestígio que cercavam as profissões até recentemente. 
Por outro lado, o surgimento de grandes empresas de saúde implica o assalariamento de grandes parcelas de profissionais até pouco tempo estabelecidos como profissionais liberais, isto é, controladores de seu tempo de trabalho, das condições em que trabalham e dos resultados de suas atividades. Neste processo, perdem seu poder de decisão e a autonomia que lhes permitia estabelecerem suas próprias regras. Nas empresas onde são assalariados, têm suas atividades organizadas e pautadas pelas regras da racionalidade econômica e da competitividade que vigoram em qualquer outro tipo de empresas (Bruno, 1986). Além disso, estão subordinados a chefias administrativas e financeiras constituídas por profissionais formados, em geral, em outras áreas de conhecimento.

Desta forma, a regulamentação profissional buscada pelos auxiliares de odontologia em nenhum aspecto se apresenta como ameaça aos dentistas. Ao contrário, acreditamos que esta regulamentação só viria ajudá-los no exercício de suas funções, uma vez que estaria definindo competências e campos de atuação que são muito distintos, embora complementares.

\section{Notas}

1 Professora do Centro Técnico Educacional da Associação Paulista de Cirurgiões Dentistas (APCD), São Paulo, Brasil. Mestre em Deontologia e Odontologia Legal pela Faculdade de Odontologia da Universidade de São Paulo (FOUSP) e Doutora em Educação pela Faculdade de Educação da Universidade de São Paulo (FEUSP). <marciaboen@uol.com.br>

2 Professora livre-docente do Departamento de Administração Escolar e Economia da Educação da Faculdade de Educação da Universidade de São Paulo (FEUSP), São Paulo, Brasil. Doutora em Sociologia pela Faculdade de Filosofia, Letras e Ciências Humanas da Universidade de São Paulo (FFLCH/USP). <lenuevo@usp.br> 
BRASIL. Parecer n ${ }^{\circ} 460$, de 6 de fevereiro de 1975, MEC/CFE. Dispõe sobre a habilitação em nível de $2^{\circ}$ grau de Técnico em Higiene Dental e Atendente de Consultório Dentário. Diário Oficial da República Federativa do Brasil, Poder Executivo, Brasília, DF, 6 fev. 1975. Documenta, v. 171, p. 20-26.

. Lei $\mathrm{n}^{\circ} 6.710$, de 5 de novembro de 1979. Dispõe sobre a profissão de Técnico em Prótese Dentária. Diário Oficial da República Federativa do Brasil. Brasília, DF, 5 nov. 1979. Disponível em: $<$ www.cfo.org.br>. Acesso em: 10 nov. 2000.

Decisão $n^{\circ} 26$, de 26 de agosto de 1984. Regulamenta o exercício das profissões de Técnico em Higiene Dental e de Atendente de Consultório Dentário. Disponível em: <www.cfo.org. br>. Acesso em: 3 mar. 2002.

. Constituição da República Federativa do Brasil (1988). Diário Oficial da República Federativa do Brasil. Brasília, DF, 5 out. 1988, seção I.

Lei $n^{\circ}$ 9.394, de 20 de dezembro de 1996. Dispõe sobre a nova Lei de Diretrizes e Bases da Educação Nacional. Diário Oficial da República Federativa do Brasil, Brasília, DF, 20 dez. 1996. Disponível em: <www.mec.gov.br/ legis/default.shtm $>$. Acesso em: 10 nov. 2000.

Decreto $\mathrm{n}^{\circ} 2.208$, de 17 de abril de 1997. Regulamenta o $\S 2^{\circ}$ do artigo 36 e os artigos 39 a 42 da LDB. Diário Oficial da República Federativa do Brasil, Brasília, DF, 17 abr. 1997. Disponível em: <www.mec.gov.br/legis/default. shtm >. Acesso em: 10 nov. 2000.

CNE/CEB. Parecer n ${ }^{\circ} 16$, de 5 de outubro de 1999. Elaboração das diretrizes curriculares nacionais para a educação profissional de nível técnico. Diário Oficial da República Federativa do Brasil, Brasília, DF, 5 out. 1999. Disponível em: <www.mec.gov.br/legis/ default.shtm>. Acesso em: 27 set. 2005.
CNE/CEB. Resolução $n^{\circ} 4$, de 5 de outubro de 1999. Institui as diretrizes nacionais para a educação profissional de nível técnico. Diário Oficial da República Federativa do Brasil. Brasília, DF, 5 out. 1999. Disponível em: <www. mec.gov.br/legis/default.shtm $>$. Acesso em: 27 set. 2005.

. Ministério da Educação e Cultura. Referenciais curriculares nacionais da educação profissional de nível técnico: área profissional saúde. Brasília, Secretaria de Educação Profissional e Tecnológica, 2000. Disponível em: $<$ http://portal.mec.gov.br/setec/index. php?option $=$ content $\&$ task $=$ view $\&$ id $=$ $74 \&$ Itemid=198>. Acesso em: 30 out. 2003. Ministério do Trabalho e Emprego. Classificação brasileira de ocupações (CBO). Brasília, DF, 2002. Disponível em: <www.mtecbo.gov.br>. Acesso em: 24 maio 2005.

Decisão $n^{\circ} 24$, de 27 de agosto de 2003. Autoriza os CROs a deferirem inscrição, como ACD, a quem requerer, apresentando declaração do exercício da atividade firmada por CD. Disponível em: <www.cfo.org.br>. Acesso em: 24 maio 2005.

Decisão $n^{\circ} 47$, de 16 de dezembro de 2003. Altera a denominação de Atendente de Consultório Dentário e dá outras providências. Disponível em: $<$ www.cfo.org.br/atos_normativos/admin pesquisa2.cfm?cod=DECIS $\% \mathrm{C} 30 \% 20 \%$ $20 \%$ >. Acesso em: 8 ago. 2005.

Ministério da Saúde. Perfil de competências profissionais do Técnico em Higiene Dental e do Atendente de Consultório Dentário. Brasília, DF, 2003. Disponível em: <www.saude.gov.br/ consultapublica $>$. Acesso em: 24 set. 2003.

Decreto $\mathrm{n}^{\circ} 5.154$, de 23 de julho de 2004. Regulamenta o $\S 2^{\circ}$ do artigo 36 e os artigos 39 a 41 da Lei de Diretrizes e Bases da Educação Nacional. Diário Oficial da República Federativa do Brasil, 
Brasília, DF, 23 jul. 2004. Disponível em: $<$ portal.mec.gov.br/setec/arquivos/pdf/ dec5154_04.pdf $>$. Acesso em: 1 abr. 2005.

BRUNO, Lucia. Educação, qualificação e desenvolvimento econômico. In:

(Org.) Educação e trabalho no capitalismo contemporâneo. São Paulo: Atlas, 1996. p. 90-123.

CONSELHO FEDERAL DE ODONTOLOGIA.

Resolução $\mathrm{n}^{\circ}$ 42, de 20 de maio de 2003. Revoga o Código de Ética Odontológica aprovado pela Resolução CFO-179/91 e aprova outro em substituição. Disponível em: <www.cfo.org.br>. Acesso em: 18 jan. 2005.
ELIAS, Norbert.; SCOTSON, John L. Os estabelecidos e os outsiders. Rio de Janeiro: Jorge Zahar, 2000.

MACHADO, Maria Helena. Sociologia das profissões: uma contribuição ao debate teórico. In: (Org.) Profissões de saúde: uma abordagem sociológica. Rio de Janeiro: Ed. Fiocruz, 1995. p. 13-33.

TARTUCE, Gisela Lobo B. Pereira. Alguns reflexos sobre a qualificação do trabalho a partir da sociologia francesa do pós-guerra. In: SGUISSARDI, Valdemar et al. (Orgs.). Educação \& Sociedade, Campinas, v. 25, n. 87 , p. 353-382, maio/ago. 2004.

Recebido em 16/07/2006

Aprovado em 10/11/2006 